\title{
Letters
}

\section{Advantages of the Socratic method for medical teaching}

I read with interest the CMAJ News article titled "Should medical educators rethink on-the-spot quizzing?"1

A recent retiree from the Department of Paediatrics at Western University (June 2021), I spent 33 years as an attending physician on the Clinical Teaching Unit in the Children's Hospital, London, Ont., supervising and teaching medical students, residents and fellows. This was in addition to working in a variety of other fields, including pediatric liver and bowel transplantation, emergency medicine, diabetes, metabolics, acquired brain injury and complex care. On retiring, I received the Department of Paediatrics Faculty Role Model Award from the residents.

On-the-spot teaching helps trainees to learn to think on their feet as physicians; it's what medical education is about. Every patient and moment is a teaching oppor- tunity. When a patient is dying in front of you, you don't have the luxury of going to the library.

During rounds, the Socratic method allows for teaching, learning and discussion. If there are problems with on-thespot teaching, they are not with the method, but the teacher. If the teacher is arrogant, lacking curiosity in the trainees, or more interested in shaming them than inviting them to share their knowledge and build on it, the teacher will fail to inspire trainees to risk and learn.

During rounds, when we had a baby with a heart murmur, I would ask all the trainees to listen and describe. When they struggled, we would go over the findings and discuss the presentation of grades of a murmur. Moving learners to understand each patient's physical findings and the subtle differences between these builds a clinician's skills and confidence. Patient bedside teaching presents countless learning opportunities. I didn't see this as a pop quiz or trial by fire; I always let the senior residents lead. If I could add, I would. Onthe-spot questioning is integral to medical education. So fix the teachers.

\section{Paul R. Atkison MD PhD}

Retired pediatrician, professor emeritus, Western University, Department of Paediatrics, London, Ont.

Cite as: CMAJ 2021 November 1;193: E1665. doi: 10.1503/cmaj.80194

\section{Reference}

1. Duong D. Should medical educators rethink onthe-spot quizzing? CMAJ 2021;193:E1182-3.

\section{Competing interests: None declared.}

Content licence: This is an Open Access article distributed in accordance with the terms of the Creative Commons Attribution (CC BY-NC-ND 4.0) licence, which permits use, distribution and reproduction in any medium, provided that the original publication is properly cited, the use is noncommercial (i.e., research or educational use), and no modifications or adaptations are made. See: https://creativecommons.org/ licenses/by-nc-nd/4.0/ 